\title{
Holistic Thinking: the Need for a Global Campaign*
}

Holism-this six-letters' word offers a meaning which contributes hugely to our understanding and management of our global ecological systems, yet, ironically, fails to attain sufficient general recognition or popular use to be included in many lexicographies. In much the same way, environmental management in the real world has only recently awakened us sufficiently to realize the merits of holistic thinking and its ecological ramifications. Holism as a concept can be considered to provide the grand meaning of the planetary system's theory, which strongly supports such structure in all our natural as well as humanengineered 'ecosystems'. In theory at least, the human perception and understanding of holism seems justified; but the practical demonstration of that understanding, as exemplified in numerous decisions, does not attest to any deep comprehension of the ecological realities involved. The global environment today in its predicament emphasizes harshly the lack of human understanding of Nature's holistic code.

The predominant feature of holism is its cosmic presence, interlacing the ecological systems at every spatial level. From mammoth to microbe, from global to local, the dynamics of the life-processes are steered by the synergistic power of holism, which, despite its potential meaning, appears to have been far less used as a term for a concept than environment. Though frequency of usage is by no means a true indication of understanding of meaning and implications, the term environment has certainly become more popular. Although used extensively by legislators, governments, private and corporate worlds, and the media, besides academics and scientists, a semantic inventory of its usage would reveal a variety of meanings and also possibly a hiatus in the required knowledge.

Notwithstanding the vast array of institutional frameworks, aimed at a judicious management of the environment, we need to initiate action based upon an introspection of our past efforts. One such important area of action is a global campaign on a holistic frame of thinking. At a time when issues such as sustainable development and global survival not only highlight the closing years of this century but herald the next with even more serious scenarios, there

*A comment on item 7 at the foot of the notepaper of the Foundation for Environmental Conservation, which reads 'World Campaign for Holistic Thinking and Concomitant Action Towards Global Survival.' is the imperative need to marshall our collective thinking towards addressing such a campaign.

A campaign for holistic thinking should, at the very outset, lay stress on the grand design of our ecological systems. Consequently it needs to underline the epistemological foundations of our understanding (or lack thereof) of that design. This is essential as science and scholarship in general are undergoing a deepening epistemological crisis, which is rendering up (or down!) fundamental questions to a fuzzy understanding. Attempts to resolve this crisis requires fresh and vigorous efforts at redesigning our methodology. Part of this campaign should be the initiation of such efforts, starting with clear definition of fundamental terms.

We therefore need to articulate a campaign for holistic thinking which we feel should be executed in two phases. Phase one needs to highlight the existing philosophical problems, while identifying the ambiguity in our definition and understanding of holistically inspired environmental decision-making. Phase two would involve a spatial analysis of holistic thinking as it prevails within the regional, continental, and global, systems. Based upon the outcome of these two phases, we could draw up a 'state of the art' analysis of holistic thinking, and offer recommendations on how effective environmental education could influence planning, policy, and legislation.

In today's information-age, a global campaign can best benefit through the newspaper, film, and television, media. Convening of conferences at the regional, continental, and global, levels, and giving interviews and teleconferences. could heighten our grounds for a common perspective on holistic thinking. That perspective would of necessity be transdisciplinary, and should be global or at least transcontinental in scope, as it has to attempt to control and regulate the transformation of our planet's environment.

Holism has the power to sustain both the natural and human-modified life-worlds in dynamic equilibrium within perceivable thresholds, but only due realization and respect for such a power would ensure intelligent decisionmaking, and reinforcement of the truth that trend is not destiny.

BHASKaR RAMACHANDRAN 12560 Neon Way Granada Hills

California 91344

USA.

\section{A Conservation Strategy for Canada's Yukon Territory}

As a step towards the development of a Yukon Conservation Strategy, a discussion paper entitled 'Building a Conservation Strategy' was released in November 1988. The paper was prepared as a cooperative venture by the Territory's Department of Renewable Resources and a public working group representing a wide range of Yukon resource and conservation interests.

This project was initiated in response to the World Conservation Strategy.* It represents a regional commitment to the report of the World Commission on Environment and Development, and Canada's National Task Force on Environment and Economy which endorsed the development of regional conservation strategies across the country. Regional initiatives, including the 1984 Task Force on Northern Conservation and an economic planning process

\footnotetext{
* See also the note by Dr David A. Munro on page 278.-Ed.
}

known as Yukon 2000, have played an important role in identifying the values which Yukoners attach to their natural world, and their desires for environmentally sound economic development. The Yukon Economic Strategy, which resulted from Yukon 2000, endorses sustainable renewable resource development and stable economic growth from the non-renewable sector, and provides a specific mandate for a conservation strategy that will function as a resource management component of the economic strategy.

\section{Public Review of Discussion Paper}

The public discussion paper outlines the principles that guide the development of the conservation strategy and contains twelve main objectives which describe environmentally and economically compatible goals-including sustainable development of the renewable resource sector, 